\title{
Oxygen permeation through oxygen ion oxide-noble metal dual phase composites
}

\author{
C.S. Chen ${ }^{a, b, *}$, H. Kruidhof ${ }^{a}$, H.J.M. Bouwmeester ${ }^{a}$, H. Verweij ${ }^{a}$, A.J. Burggraaf ${ }^{a}$ \\ a Laboratory of Inorganic Materials and Science, Faculty of Chemical Technology, University of Twente, P.O. Box 217. \\ 7500 AE Enschede, The Netherlands \\ 'Department of Materials Science and Engineering, University of Science and Technology of China, Hefei, Anhui 230026, China
}

\begin{abstract}
Oxygen permeation behaviour of three composites, yttria-stabilized zirconia-palladium, erbia-stabilized bismuth oxidenoble metal (silver, gold) was studied. Oxygen permeation measurements were performed under controlled oxygen pressure gradients at elevated temperatures. Air was supplied at one side of a dense sintered disk specimen, while helium was fed at the opposite side to sweep away the permeated oxygen. This research has demonstrated that in addition to the presence of percolative metal phase in the oxide matrix, a large ionic conductivity of the oxide phase and a high catalytic activity of the metal phase towards surface oxygen exchange are required for the dual phase composite to possess high oxygen permeability. The bismuth oxide-silver composite fulfils these requirements, hence showing the best oxygen permeability.
\end{abstract}

Keywords: Dual phase composites; Oxygen permeation; Ion conductivity

\section{Introduction}

Oxygen ion-electron mixed conducting materials are building stones of a variety of solid state electrochemical devices. Recent studies have shown that the mixed conducting materials also promise well as oxygen separation membranes, since they are permeable only to oxygen while impervious to other gaseous constituents $[1,2]$. The unique transport property of the membranes may result in a wide range of applications, especially in high temperature oxygen separators and chemical reactors. Envisioned applications of the oxygen separators range from small-scale oxygen pumps for home medical care to large scale use in combustion processes. The po-

\footnotetext{
${ }^{*}$ Corresponding author.
}

tential application of the membrane chemical reactors is the selective feeding (or extracting) of oxygen into chemical reactors, e.g., in hydrocarbon oxidation and dehydrogenation processes.

Dual phase composite membranes made of an oxygen ion-conducting oxide and an electron-conducting metal show a large oxygen permeability and relatively good chemical and mechanical stability at elevated temperatures [3,4], Oxygen permeation through the membranes involves an oxygen ionionic current through the oxide phase and an electronic current through the metal phase. It also involves surface oxygen exchange at the three-phase boundary of the oxide/metal/gas. This paper is intended to identify the factors affecting the oxygen permeability of the membranes by comparing the oxygen permeation behaviour of three composites, 
yttria-stabilized zirconia-palladium, erbia-stabilized bismuth oxide-noble metal (silver, gold).

\section{Experimental}

Three crack-free composites with densities above $95 \%$ were prepared: one containing $60 \mathrm{v} / \mathrm{o}$ yttriastabilized zirconia and $40 \mathrm{v} / \mathrm{o}$ palladium (ZYPd), one containing erbia-stabilized bismuth oxide ( 60 $\mathrm{v} / \mathrm{o})$ and silver $(40 \mathrm{v} / \mathrm{o})(\mathrm{BEAg})$, and one containing erbia-stabilized bismuth oxide $(60 \mathrm{v} / \mathrm{o})$ and gold (40 $\mathrm{v} / \mathrm{o})(\mathrm{BEAu})$. The details of sample preparation have been described elsewhere [4,5].

Prior to oxygen permeation measurements, the sintered composites were sliced into disks with desired dimensions. The thickness of ZYPd, BEAg and BEAu was $1.72,1.60$ and $1.00 \mathrm{~mm}$ respectively, and the diameter $12.0,15.0$ and $15.0 \mathrm{~mm}$ respectively. The experimental set-up and measurement procedures have been described elsewhere in detail [6]. The disks were sealed into a quartz reactor using a glass ring in air. Oxygen permeation measurements were performed in the range of $800-1100^{\circ} \mathrm{C}$ for the zirconia-based sample and $650-850^{\circ} \mathrm{C}$ for the bismuth oxide based samples. Air was supplied at one side of the dense sintered disk specimen, while helium was fed at the opposite side to carry away the permeated oxygen. The oxygen and nitrogen concentrations in the helium at the gas outlet were analyzed by on-line gas chromatography (GC) (Varian model 3400 ). The observation that no nitrogen was detected by $\mathrm{GC}$ indicated that the seal was appropriate and the membrane was gas-tight.

Due to the glass sealing the accessible surface area at the permeate side of the membrane was smaller than that at the feed side. This asymmetric configuration of the membrane complicates the flux profile in the bulk of the membrane. Therefore a proper data processing procedure must be used. In this study, oxygen flux was normalized for the total accessible surface area at the permeate side. The oxygen permeance $F$ of the membrane was calculated by dividing the flux with the Nernst potential $[2,5]$. For correcting the effect of the asymmetric membrane configuration, the as-obtained permeance value was divided by a factor of $G$. The value of $G$ was obtained by two dimensional simulations [2,7]. For samples ZYPd, BEAg and BEAu the value of $G$ was $1.24,1.15$ and 1.34 respectively.

\section{Results and discussion}

The oxygen flux through the composite membranes is plotted in Fig. la. The permeance, i.e., the flux-per-unit driving force, is given in Fig. 1b. It can be seen from Fig. 1a-b that all the three composites
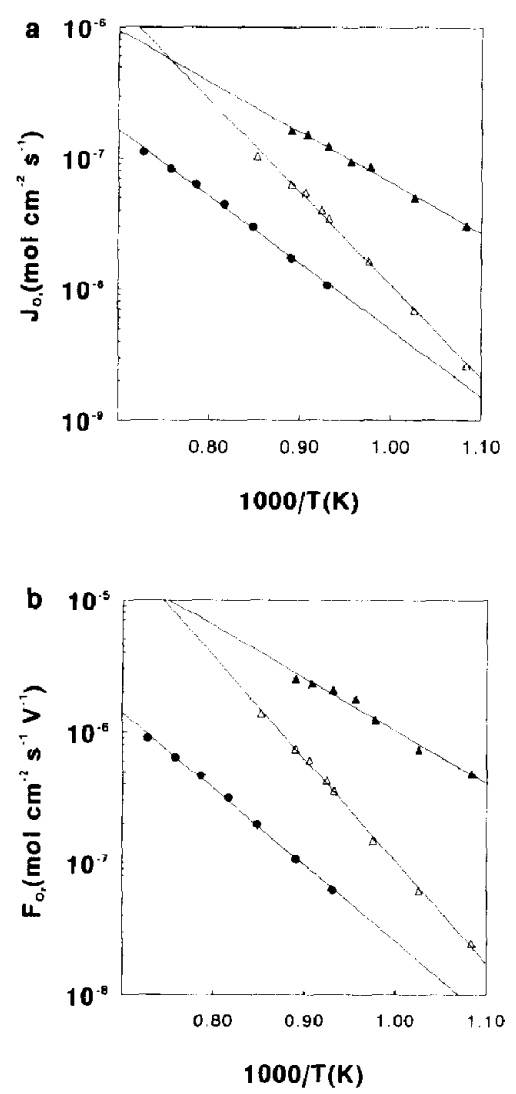

Fig. 1. Temperature dependence of (a) oxygen flux and (b) permeance. Oxygen pressure at the feed side was maintained at 0.209 atm during the measurements. (O) a $1.72 \mathrm{~mm}$ thick zirconia-palladium composite: $p_{\mathrm{O}_{2}}\left(\mathrm{I}_{1100^{\circ} \mathrm{C}}=0.0093 \mathrm{~atm}\right.$, $p_{\mathrm{O}_{2}}(l)_{850^{\circ} \mathrm{C}}=0.0015 \mathrm{~atm}$. $(\Delta)$ a $1.00 \mathrm{~mm}$ thick bismuth oxide-gold composite: $p_{\mathrm{O}_{2}}(1)_{850^{\circ} \mathrm{C}}=0.0096 \mathrm{~atm}, p_{\mathrm{O}_{2}}(1)_{650^{\circ} \mathrm{C}}=0.0020 \mathrm{~atm}$. (A) a $1.60 \mathrm{~mm}$ thick hismuth oxide-silver composite: $p_{o_{2}}(1)_{850^{\circ} \mathrm{C}}=$ $0.024 \mathrm{~atm}, p_{\mathrm{O}_{2}}(1)_{\mathrm{G} 50^{\circ} \mathrm{C}}=00.016 \mathrm{~atm}$. 
show large permeability at elevated temperatures. For the $1.60 \mathrm{~mm}$-thick bismuth oxide-silver composite an oxygen flux of $1.19 \times 10^{-7} \mathrm{~mol} \mathrm{~cm}^{-2} \mathrm{~s}^{-1}$ was observed at $800^{\circ} \mathrm{C}$ under conditions that the oxygen partial pressure at the feed side of the membrane was $0.209 \mathrm{~atm}$ and oxygen partial pressure at the permeate side, $p_{\mathrm{O}_{2}}(1)$, was $0.026 \mathrm{~atm}$. For the $1.03 \mathrm{~mm}$ thick bismuth oxide-gold composite, the measured oxygen flux was $3.4 \times 10^{-8} \mathrm{~cm}^{-2} \mathrm{~s}^{-1}$ at $p_{\mathrm{O}}(1)=0.0015 \mathrm{~atm}$. For the $1.72 \mathrm{~mm}$ thick zirconiapalladium composite an oxygen flux of $1.06 \times 10^{-8}$ mol cm $\mathrm{s}^{-1}$ was measured at $p_{\mathrm{O}_{2}}(1)=0.0009 \mathrm{~atm}$.

The oxygen permeability of the composites is two to three orders of magnitude higher than that of the pure oxides $[6,8]$. This is because in these dual phase composites the metal phase forms a continuous, percolative network [4]. In percolative composites, oxygen ions and electrons transport through oxide and metal phase respectively, creating a non-vanished internal current. As a result, oxygen molecular flux is continuously transferred from the high $p_{\mathrm{O}_{2}}$ side of the composite to the low $p_{\mathrm{O}_{2}}$ side.

It can be secn from Fig. 1 that the oxygen permeability of the zirconia-palladium composite is much lower than that of the bismuth oxide-silver composite. A separate study showed that the oxygen permeance of the zirconia-palladium composite is inversely proportional to the thickness of the membrane when the thickness of the membrane is larger than about $1 \mathrm{~mm}$ [2]. This reveals that oxygen permeation through the zirconia-palladium composite is in the bulk controlled region. Evidence also emerges from the study on the bismuth oxide-silver composites [5] that oxygen permeation through the composites is mainly controlled by the bulk process. The bulk process of the oxygen permeation consists of two sub-processes: oxygen transport through the oxide phase and electron migration through the metal phases. Since the metal phase forms a continuous phase and is well percolative, the electronic resistance of the metal phase is negligible compared to the ionic resistance of the oxide. In other words, the oxygen-ion conduction through the oxide is the rate-limiting step, thus the oxygen flux is proportional to the oxygen-ionic conductivity $[2,5]$. The ionic conductivity of the erbia-stabilized bismuth oxide is one to two orders higher than that of the yttria-stabilized zirconia [9], corresponding to the difference in oxygen permeability between the zirconia-based composite and the bismuth oxide-based one.

It can also been observed from Fig. 1 that for bismuth oxide-based composites, the silver-containing composite has a higher oxygen permeability than the gold-containing one. This difference is attributed to the difference of the metals in the surface oxygen exchange activity. Silver is by far the best oxygen electrode material on oxygen ionic conductors in terms of polarizability and electrode resistance [10]. Therefore, the oxygen exchange process at the surface of silver-containing composite is sufficiently fast, thus imposing no limitation on the overall oxygen permeation process. However, gold is inert to the surface process. The activation energy obtained for oxygen permeation through the gold-containing composite (BEAu) is $148 \pm 3 \mathrm{~kJ}$, which is close to $145 \pm 7 \mathrm{~kJ}$, the value obtained from the temperature dependence of exchange current density of $\mathrm{Au}$ electrodes on BE25 [11]. This strongly suggests that the surface oxygen exchange process is the rate limiting step for the oxygen permeation through the gold-containing composites.

\section{Conclusions}

From present studies in combination with previous work studies, it can be concluded that for dual phase composites to show a large oxygen permeability, the following requirements must be met: (a) percolation of electronic conducting metal phase in oxide matrix, allowing electrons to pass through, (b) a large ionic conductivity of the oxide phase, allowing oxygen ions to migrate through and (c) a large catalytic activity of the metal phase towards surface oxygen exchange. The bismuth oxide-silver composite fulfils these requirements, showing the best oxygen permeability. For example, for a 1.60 mm-thick bismuth oxide-silver composite an oxygen flux of $1.19 \times 10^{-7}$ mol cm $\mathrm{cm}^{-2} \mathrm{~s}^{-1}$ was observed at $800^{\circ} \mathrm{C}$ under conditions that $p_{\mathrm{O}_{2}}(\mathrm{~h})=0.21$ atm and $p_{\mathrm{O}_{2}}(1)=0.026 \mathrm{~atm}$. The dual phase composites are promising to find applications in oxygen separation, oxygen-enrich combustion and catalytic membrane reactors. 


\section{Acknowledgments}

The investigations were supported by The Netherlands Foundation for Chemical Research with financial aid from The Netherlands Organization for Scientific Research (NWO).

\section{References}

[1] H.J.M. Bouwmeester, H. Kruidhof and A.J. Burggraaf, Solid State Ionics 72 (1994) 185.

[2] C.S. Chen, PhD thesis, University of Twente, The Netherlands, 1994.

[3] T.J. Mazanec, T.L. Cable and J.G. Frye., Solid State Ionics 53-56 (1992) 111.

[4] C.S. Chen, B.A. Boukamp, H.J.M. Bouwmeester, G.Z. Cao, H. Kruidhof, A.J.A. Winnubst, A.J. Burggraaf, Solid State Ionics 76 (1995) 23.
[5] C.S. Chen, H. Kruidhof, H.J.M. Bouwmeester, H. Verweij and A.J. Burggraaf, Oxygen permeation through stabilized bismuth oxide-noble metal composites, Solid State Ionics, submitted for publication.

[6] H.J.M. Bouwmeester, H. Kruidhof, A.J. Burggraaf and P.J. Gellings, Solid State Ionics 53-56 (1992) 460.

[7] D. Britz, Lecture Notes in Chemistry in: Digital Simulation in Electrochemistry (Springer Verlag, Berlin, Heidelberg, New York, 1981).

[8] J. Fouletier, P. Fabry and M. Kleitz, J. Electrochem. Soc. 123 (1976) 204.

[9] M.J. Verkerk, K. Keizer and A.J. Burggraaf, J. Appl. Electrochem. $10(1980) 81$.

[10] M. Kleitz, T. Kloid and L. Dessemond, in: Proc. of 14th Ris $\emptyset$ Inter. Symp. on Materials Science (1991) p. 89.

[11] I.C. Vink, K. Seshan, B.A. Boukamp, K.J. de Vries and A.J. Burggraaf, Solid State Ionics 34 (1989) 235. 